\title{
Analisis Kebutuhan Pengembangan Laboratorium PGMI dalam Perkuliahan IPA
}

\author{
Suyatman \\ Fakultas IImu Tarbiyah dan Keguruan IAIN Surakarta \\ e-mail: paksuyatman@yahoo.co.id
}

\begin{abstract}
Based on documentation of pgmi mentioned that college students are derived from background science class is $36,98 \%$, less than $50 \%$ of the student PGMI .This has led consequence that lecture believe in science ranging from the base and supported by the laboratory adequate. The laboratory adequate will build real kosep students in understand science.Steps analysis needs research laboratory PGMI in lecture ipa is as follows: 1) analysis of need assessment, 2) the literature study, 3) study komparasi , 4) expert judgment, 5) improvement. Based on analysis of the data can pull conclusions as follows: 1) The lab PGMI FITK IAIN Surakarta especially for science laboratory having 85 set equipment consisting of 737 the tools and can be used to 121 title science experiments. 2) Additional needs necessary the 25 set equipment science experiments, with details as follows: kit science less 24 set, consisting of the balance KIT 4 sets, mineral KIT 5 sets, Sound KIT 4 sets, coal KIT 6 sets, and heat engine KIT 5 sets, and science integrated KIT less 1 set, and 5 the microscopes
\end{abstract}

Keywords: analysis needs, the development of a laboratory, IPA lecture 


\section{Pendahuluan}

PGMI (Pendidikan Guru Madrasah Ibtida'iyah) Fakultas Ilmu Tarbiyah dan Keguruan (FITK) IAIN Surakarta merupakan program studi baru, menerima pendaftaran mahasiswa baru mulai tahun Akademik 2014/2015. Pada tahun Akademik 2014/2015 jumlah mahasiswa jurusan PGMI 73 orang, dari berbagai latar belakang pendidikan yang berbeda tampak seperti pada tabel berikut:

Tabel. 1. Gambaran Mahasiswa PGMI

\begin{tabular}{|l|c|c|c|c|c|}
\hline $\begin{array}{c}\text { Asal } \\
\text { Sekolah }\end{array}$ & $\begin{array}{c}\text { Jumlah } \\
\text { Mhs }\end{array}$ & Persentase & $\begin{array}{c}\text { Asal } \\
\text { Jurusan }\end{array}$ & $\begin{array}{c}\text { Jumlah } \\
\text { Mhs }\end{array}$ & Persentase \\
\hline SMA & 22 & $30,13 \%$ & IPA & 27 & $36,98 \%$ \\
\hline MA & 37 & $50,58 \%$ & IPS & 26 & $35,62 \%$ \\
\hline SMK & 14 & $19,17 \%$ & Lainnya* & 20 & $27,40 \%$ \\
\hline
\end{tabular}

(sumber: Dokumen Jurusan PGMI)

*Lainnya: elektro, tata busana, multimedia, administrasi, akuntasi, pemasaran, agama, dan otomotif.

Dari data, pada tabel di atas tampak bahwa mahasiswa yang berasal dari latarbelakang jurusan IPA ada 36,98 \%, kurang dari 50\% dari keseluruhan mahasiswa Jurusan PGMI. Hal ini membawa konsekuensi bahwa perkuliahan IPA semestinya di mulai dari dasar dan didukung dengan laboratorium yang memadai. Laboratorium yang memadai akan membangun kosep riil mahasiswa dalam memahami IPA.

Selain itu, di dalam buku Panduan Akadmik 2014/2015 IAIN Surakarta (2014: h.134) disebutkan bahwa salah satu tujuan dari Jurusan PGMI adalah menghasilkan temuan-temuan inovatif dalam bidang kependidikan Madrasah Ibtida'iyah dan yang sederajat (tujuan no.2). Selain itu, Jurusan PGMI diharapkan mampu menghasilkan produk-produk inovatif dalam bidang kependidikan ditingkat Madrasah Ibtida'iyah

Tujuan dan harapan tersebut di atas perlu adanya faktor pendukung diantaranya kurikulum yang mampu mengejawantahkan tujuan dan harapan tersebut, SDM (Sumber Daya Manusia) terutama dosen yang handal, serta sarana dan prasarana yang memadai. Kurikulum sudah dirancang dengan porsi yang memadai, dan para dosen di PGMI semua sudah mempunyai pendidikan S2, bahkan beberapa dosen sudah S3, sesuai dengan bidang keilmuannya. Sedangkan sarana dan prasarana secara umum cukup 
memadai, namun tujuan prodi PGMI tersebut di atas sulit untuk terwujud hanya dengan mengandalkan sarana dan prasarana yang dimiliki pada saat ini.

Tujuan yang dicanangkan di atas memerlukan sarana dan prasarana yang lebih khusus diantaranya yaitu: Laboratorium PGMI yang konprehensif. Pada saat ini data yang dimiliki laboratorium Jurusan PGMI dari hasil obsevasi peneliti yaitu: alat peraga seperti torso manusia 2 buah, microskop digital 2 buah, dan beberapa KIT IPA seperti pada tabel berikut:

Tabel. 2. Laboratorum PGMI

\begin{tabular}{|c|c|c|c|}
\hline No & Jenis Peralatan & Jumlah & Keterangan \\
\hline 1 & Kit IPA & $11 \mathrm{Kit}$ & \multirow{2}{*}{$\begin{array}{l}\text { Dapat digunakan } 46 \text { judul } \\
\text { percobaan }\end{array}$} \\
\hline 2 & Peralatan IPA & 57 buah & \\
\hline 3 & Poster & 8 buah & \multirow{3}{*}{$\begin{array}{l}\text { Dapat digunakan dalam } 10 \\
\text { tema aktivitas pembelajaran }\end{array}$} \\
\hline 4 & Kartu Pembelajaran & 43 kartu & \\
\hline 5 & Apron & 13 Apron & \\
\hline
\end{tabular}

(sumber: Hasil Observasi di Lab PGMI, 24 April 2015)

Dari data di atas, belumlah lengkap bagi calon guru MI yang seharusnya menguasi materi IPA di MI mulai kelas 1 sampai kelas VI. Padahal adanya laboratorium yang lengkap maka akan dapat digunakan praktikum mahasiswa secara konprehensif. Praktikum dapat membangkitkan motivasi belajar, praktikum mengembangkan keterampilan dasar melakukan eksperimen, praktikum menjadi wahana belajar pendekatan ilmiah, dan praktikum memberikan kesempatan untuk menemukan teori, serta membuktikan teori. Secara singkat dapat dikatakan bahwa laboratorium dapat menumbuhkan dan mengembangkan aspek-aspek psikomotor, dan proses berpikir.

Berdasarkan uraian Latar Belakang Masalah di atas dapat dirumuskan masalah sebagai berikut: 1) Bagaimanakah kondisi daya dukung Laboratorium PGMI dalam perkuliahan IPA mahasiswa PGMI? 2) Seperti apakah kebutuhan Laboratorium PGMI dalam perkuliahan IPA mahasiswa PGMI?

Adapun tujuan yang ingin dicapai dalam penelitian ini adalah sebagai berikut: 1) Untuk mengetahui kondisi daya dukung Laboratorium PGMI dalam perkuliahan IPA 
mahasiswa PGMI. 2) Untuk mengetahui kebutuhan Laboratorium PGMI dalam perkuliahan IPA mahasiswa PGMI.

Dari hasil penelitian ini diharapkan dapat memberikan manfaat antara lain sebagai berikut: 1) Hasil penelitian ini dapat dimanfaatkan sebagai pedoman untuk inventarisasi Laboratorium PGMI. 2) Hasil penelitian ini dapat digunakan sebagai acuan dalam mengembangkan Laboratorium PGMI.

Secara sempit laboratorium diartikan sebagai ruangan yang dibatasi oleh dinding yang di dalamnya terdapat alat-alat dan bahan-bahan beraneka ragam yang dapat digunakan untuk melakukan eksperimen (Subiyanto, 1998 : 79). Sudaryanto (1998 : 2) mendefinisikan laboratorium sebagai salah satu sarana pendidikan IPA, sebagai tempat peserta didik berlatih dan kontak dengan objek yang dipelajari secara langsung, baik melalui pengamatan maupun percobaan.

Lebih lanjut Sudaryanto (1998: 7) menyatakan peranan dan fungsi laboratorium ada tiga, yaitu sebagai (1) sumber belajar, artinya lab digunakan untuk memecahkan masalah yang berkaitan dengan ranah kognitif, afektif, dan psikomotor atau melakukan percobaan, (2) metode pendidikan, meliputi metode pengamatan dan metode percobaan, dan (3) sarana penelitian, tempat dilakukannya berbagai penelitian sehingga terbentuk pribadi peserta didik yang bersikap ilmiah.

Dari beberapa pendapat di atas dapat ditegaskan bahwa dengan adanya Laboratorium IPA, maka diharapkan proses perkuliahan IPA dapat dilaksanakan seoptimal mungkin, meskipun bukan berarti perkuliahan IPA di PGMI tidak dapat diajarkan tanpa laboratorium. Dari sisi ini tampak betapa penting peranan Laboratorium IPA untuk mencapai tujuan dalam perkuliahan.

\section{Peran Strategis Laboratorium IPA}

Ada 4 alasan yang menguatkan peran Laboratorium IPA dalam pembelajaran antara lain: 1) Praktikum membangkitkan motivasi belajar IPA. Dalam belajar, mahasiswa dipengaruhi oleh motivasi. Mahasiswa yang termotivasi untuk belajar akan bersungguh-sungguh dalam mempelajari sesuatu. Melalui kegiatan laboratorium, mahasiswa diberi kesempatan untuk memenuhi dorongan rasa ingin tahu dan ingin bisa. Prinsip ini akan menunjang kegiatan praktikum di mana mahasiswa menemukan 
pengetahuan melalui eksplorasi. 2) Praktikum mengembangkan keterampilan dasar melakukan eksperimen. Kegiatan eksperimen merupakan aktivitas yang banyak dilakukan oleh ilmuwan. Untuk melakukan eksperimen diperlukan beberapa keterampilan dasar seperti mengamati, mengestimasi, mengukur, membandingkan, memanipulasi peralatan laboratorium, dan ketrampilan sains lainnya. Dengan adanya kegiatan praktikum di laboratorium akan melatih mahasiswa untuk mengembangkan kemampuan bereksperimen dengan melatih kemampuan mereka dalam mengobservasi dengan cermat, mengukur secara akurat dengan alat ukur yang sederhana atau lebih canggih, menggunakan dan menangani alat secara aman, merancang, melakukan dan menginterpretasikan eksperimen. 3) Praktikum menjadi wahana belajar pendekatan ilmiah. Para ahli meyakini bahwa cara yang terbaik untuk belajar pendekatan ilmiah adalah dengan menjadikan mahasiswa sebagai ilmuwan. Pembelajaran sains sebaiknya dilaksanakan melalui pendekatan inkuiri ilmiah (scientific inquiry) untuk menumbuhkan kemampuan berpikir, bekerja dan bersikap ilmiah serta mengkomunikasikannya sebagai aspek penting kecakapan hidup. Oleh karena itu pembelajaran sains mulai dari tingkat dasar sampai perguruan tinggi menekankan pada pemberian pengalaman belajar secara langsung melalui penggunaan dan pengembangan keterampilan proses dan sikap ilmiah. 4) Praktikum menunjang materi pelajaran. Praktikum memberikan kesempatan bagi mahasiswa untuk menemukan teori, dan membuktikan teori. Selain itu praktikum dalam pembelajaran sains dapat membentuk ilustrasi bagi konsep dan prinsip sains. Dari kegiatan tersebut dapat disimpulkan bahwa praktikum dapat menunjang pemahaman mahasiswa terhadap materi pelajaran. (Rustaman, 1995).

\section{Alat Peraga IPA}

Dalam Kamus Bahasa Indonesia (2001), Alat peraga yaitu alat yang digunakan dalam pengajaran yang dapat dilihat sehingga tahu benar yang dimaksud atau sebagai alat bantu untuk menghitung dan sebagainya. Sedangkan Menurut Moejadi (1994: 35) mengatakan bahwa: Alat peraga adalah suatu alat biasanya tidak dalam bentuk perangkat (set), yang jika digunakan dapat membantu memudahkan memahami suatu konsep secara tidak langsung. Yang termasuk dalam kelompok ini ialah model, cara, 
dan poster. Alat peraga dibuat karena barang atau alat yang sebenarnya sulit dihadirkan dalam ruang belajar.

Berdasarkan penjelasan di atas dapat disimpulkan bahwa alat peraga dapat digunakan untuk memahami suatu konsep yang dapat ditampilkan pada saat proses pembelajaran. Mengajarkan mata pelajaran tidak cukup hanya dengan menggunakan kapur dan papan tulis saja. Sekarang ini tuntutan pembelajaran tidak hanya memberikan sejumlah fakta, yang makin lama jumlahnya makin banyak yang harus dihafalkan, tetapi mahasiswa juga harus dapat menjelaskan mengapa fakta itu ada, bagaimana fakta itu terjadi, dan di mana fakta itu dapat terjadi.

Agar mahasiswa dapat memahami seluruh tuntutan pembelajaran itu, tidak cukup dengan hanya memberikan ceramah. Menurut Moejadi (1994) pemberian ceramah kepada mahasiswa berarti telah menjejali dengan fakta-fakta yang harus ia serap atau bila tidak harus ia hafalkan. Lain halnya jika diberikan dengan menggunakan alat peraga, maka kata-kata dosen akan menjadi lebih singkat dan mahasiswa akan lebih mudah memahami dan menyerap penjelasan dosen.

Menurut Hardanawati (2000:65) memgatakah bahwa : Model adalah tiruan dari benda sebenarnya, bentuknya ada yang lebih besar dan ada pula yang lebih kecil dari benda sebenarnya. Model baik untuk mengajarkan konsep tentang benda yang berdimensi tiga dan konkret. Contoh dibuat model bumi (globe) karena tidak mungkin bagi dosen untuk menghadirkan bumi dalam ruang kelas. Dengan model bumi mahasiswa dapat melihat bentuk dan gambaran bagian-bagian bumi dengan jelas.

Berdasarkan pendapat di atas disimpulkan bahwa banyak model dibuat untuk menunjukkan bagian dalam suatu benda agar bagian itu dapat diamati dengan mudah. Model biasanya dibuat lebih sederhana dan tidak rumit dengan maksud agar konsepkonsep dasar yang ingin dipelajari dapat di amati. Sebagai pengganti benda yang sebenarnya, maka model harus dibuat dengan sangat teliti, dan tidak memberikan informasi yang salah.

Beberapa keuntungan penggunaan model menurut Moejadi (1994), dalam proses belajar mengajar yaitu : (1) model merupakan benda tiga dimensi yang menyerupai benda yang sebenarnya, (2) model dibuat menurut ukuran yang sesuai dengan keperluan, (3) model dibuat untuk memperlihatkan bagian dalam benda yang 
dipelajari, (4) model dibuat untuk menunjukkan bagian-bagian yang penting saja, (5) model dibuat untuk dibongkar bagian-bagiannya dan kemudian dipasang kembali, (6) model dapat meningkatkan aktivitas dan minat belajar.

Selain jenis alat peraga berupa model, alat peraga lain yang sering digunakan adalah gambar atau foto. Gambar merupakan alat peraga penting. Alat ini penting karena gambar dapat memberikan informasi yang diperlukan tentang benda atau masalah yang digambarnya. Seperti halnya model, gambar berfungsi sebagai pengganti benda aslinya. Jika benda atau peristiwa yang sebenarnya itu tidak mungkin didatangkan di ruang belajar, maka biasanya digunakan gambar sebagai penggantinya. Dipilih gambar sebagai pengganti karena gambar mudah didapat dan mudah membuatnya.

Beberapa keuntungan menggunakan gambar menurut Sukarno (1994), sebagai alat peraga adalah: (1) gambar mudah diperoleh baik dengan cara menggambar sendiri atau diperoleh dari koran atau majalah, (2) gambar mudah digunakan dan tanpa memerlukan alat bantu, (3) gambar dapat diperbesar atau diperkecil dengan beberapa cara, di antaranya dengan metode petak-petak, pantograf, atau dengan cara memfotocopi, (4) dengan menggunakan OHP (overhead projector) gambar dapat diproyeksikan pada layar dengan lebih dulu memfotocopi gambar tersebut pada lembar transparan. Hal ini dilakukan jika gambar ingin diperbesar sementara dan dilihat oleh banyak siswa.

Berdasarkan uraian tersebut di atas, maka dapat disimpulkan bahwa penggunaan alat peraga dalam proses belajar mengajar dapat membantu mahasiswa untuk mempermudah memahami suatu konsep atau prinsip yang diajarkan, membantu guru dalam proses belajar mengajar, dan membuat mahasiswa lebih aktif belajar. Dalam Arsyad (2004), Alat peraga memiliki kelebihan sebagai berikut (a) umumnya murah harganya, (b) mudah didapat, (c) mudah digunakannya, (d) dapat memperjelas suatu benda, (e) lebih realistis, (f) dapat membantu mengatasi keterbatasan pengamatan, (g) dapat mengatasi keterbatasan ruang dan waktu. Namun demikian alat peraga juga mamiliki keterbatasan, antara lain (a) semata-mata hanya media visual, (b) ukuran gambar sering sekali kurang tepat untuk pengajaran dalam kelompok besar, (c) 
memerlukan keterbatasan sumber dan keterampilan, dan kejelasan guru untuk dapat memanfaatkanya.

\section{KIT IPA (Ilmu Pengetahuan Alam)}

Kit IPA merupakan alat-alat yang digunakan untuk percobaan dalam pembelajaran IPA " (Trisnoherawati, 2004:1). Sedangkan Menurut Wibawa dan Mukti "Alat peraga KIT IPA atau loan boxes merupakan salah satu dari media tiga dimensi". Media tiga dimensi dapat memberi pengalaman yang mendalam dan pemahaman yang lengkap akan benda-benda nyata. "Loan boxes adalah kotak yang mempunyai bentuk dan besarnya sesuai dengan keperluan". "Kotak ini diisi dengan item-item yang berhubungan dengan unit pelajaran" (Hamalik, 1994: 157).

Dari uraian di atas dapat disimpulkan bahwa KIT IPA adalah kotak yang berisi seperangkat peralatan yang digunakan sebagai alat peraga dalam pembelajaran Ilmu Pengetahuan Alam yang mempunyai bentuk dan besaran sesuai dengan keperluan. Trisnoherawati (2004:13) mengemukakan bahwa peran KIT IPA sebagai berikut: 1) untuk meningkatkan mutu pengajaran dan pembelajaran IPA di Sekolah Dasar, 2) untuk menekankan pada metode-metode pembelajaran interaktif, 3) untuk mengembangkan program pengembangan sumber daya manusia, 4) untruk menciptakan tenaga kerja yang lebih bermutu, 5) untuk memenuhi tujuan pembangunan masyarkat, ekonomi, dan teknik, 6) untuk membantu dosen IPA, mempermudah persiapan pengajaran dan memperbaiki mutu proses belajar mengajar di kelas.

Penggunaan media KIT IPA seperti telah disampaikan diatas mampu membantu siswa dalam meningkatkan motivasi siswa sehingga hasil belajarnya meningkat. Karakteristik dan tujuan pembuatan KIT IPA diarahkan untuk membantu mempermudah penguasaan materi. KIT menunjukkan gejala-gejala alam dalam bentuk peragaan, daftar nama benda dan bahan dari lingkungan yang diperlukan untuk percobaan tertentu, gambar-gambar atau informasi penting yang disampaikan oleh guru.

\section{Manajemen Laboratorium IPA}

Manajemen adalah kemampuan dan keterampilan khusus untuk melakukan suatu kegiatan, baik bersama orang lain maupun melalui orang lain dalam mencapai 
tujuan organisasi (Sudjana, 2000:17). Manajemen juga diartikan sebagai proses penggunaan sumber daya secara efektif untuk mencapai tujuan tertentu (The General Safety Committee, 1954 : 3). Dalam manajemen terkandung di dalamnya pengelolaan terhadap suatu objek. Jadi, manajemen laboratorium berarti objek yang akan dimanajemen adalah laboratorium tersebut yang secara rinci terdiri dari alat-alat dan bahan-bahan, sarana/prasarana lab, dan proses pelaksanaan praktikum.

Fungsi manajemen adalah sebagai rangkaian kegiatan wajar yang telah ditetapkan dan memiliki hubungan saling ketergantungan antara satu dengan yang lain. Sejalan dengan perkembangan jaman, maka para pakar mengemukakan berbagai fungsi manajemen yang dikenal dengan POCCC, yaitu : Planning (perencanaan), Organizing (pengorganisasian), Commanding (perintah), Coordinating (pengkoordinasian), dan Controlling (pengawasan).

Pendapat lain tentang fungsi manajemen ini dikemukakan oleh Gullick yang meliputi 6 urutan, yaitu Planning, Organizing, Staffing, Directing, Coordinating, Reporting, dan Budgeting (disingkat POSCORB). Hersey dan Blanchard membagi fungsi manajemen menjadi empat, yaitu Planning, Organizing, Motivating, dan Controlling (disingkat POMC). Pendapat lain dikemukakan oleh Terry (1977 : 18) yang mengemukakan fungsi manajemen menjadi empat, yaitu Planning, Organizing, Actuating, dan Controlling (disingkat POAC).

\section{Metode Penelitian}

Penelitian ini merupakan penelitian pengembangan, karena ingin menganalisis kebutuhan Laboratorium PGMI dalam perkuliahan IPA. Data-data yang akan diperoleh selama melakukan penelitian dapat dikelompokkan menjadi dua jenis data, yaitu: 1) Data Primer, data ini diperoleh melalui pengambilan data dari Laboratorium PGMI di FITK IAIN Surakarta. 2) Data Sekunder, data ini diperoleh dari berbagai sumber yang berhubungan dengan judul dalam penelitian ini, diantaranya Pejabat Jurusan PGMI, Dosen IPA PGMI dan Mahasiswa PGMI.

Teknik pengumpulan data yang digunakan dalam penelitian ini digolongkan menjadi dua bagian yaitu: 1) Studi Pustaka, yaitu metode pengumpulan bahan kepustakaan dengan mempelajari dan mengutip ke dalam penulisan ilmiah guna melengkapi landasan teori serta pembahasan data dari dokumen yang ada sebagai dasar dalam menganalisis kebutuhan Laboratorium PGMI dalam perkuliahan IPA. 2) Studi Lapangan, adalah pengumpulan data yang

| Volume. 1, No. 1, Januari - Juni 2016 
dilakukan secara langsung yang diperoleh dengan cara: a). Mengidentifikasi Alat Peraga dan KIT IPA yang ada di Laboratorium PGMI; baik jenis, jumlah dan keadaannya b). wawancara yaitu pengumpulan data dengan cara mewawancari responden tentang kebutuhan Alat Peraga dan KIT IPA kepada Pejabat Jurusan, Dosen IPA PGMI, dan Mahasiswa PGMI.

Langkah-langkah penelitian Analisis Kebutuhan Laboratorium PGMI dalam Perkuliahan IPA adalah sebagai berikut: (1) Analisis Need Assessment (2) Studi pustaka (3) Studi komparasi (4) Expert Judgment (5) Penyempurnaan.

Teknik analisis data yang diaplikasikan dalam pengolahan data yaitu dengan menggunakan analisis isi. Analisis isi digunakan untuk mengolah data data lapangan dari hasil inventarisasi alat peraga IPA dan KIT IPA yang ada di Laboratorium PGMI, serta hasil wawancara dengan Pejabat Jurusan, Dosen IPA PGMI, dan Mahasiswa PGMI. Hasil analisis ini kemudian digunakan sebagai dasar untuk menentukan kebutuhan Laboratorium PGMI dalam Perkuliahan IPA.

\section{Pembahasan}

Laboratorium PGMI FITK IAIN Surakarta berisikan berbagai media pembelajaran, khusus untuk pembelajaran IPA terbagi menjadi 7 kategori yaitu: KIT IPA, KIT IPA Terintegrasi, Model, Poster, Kartu, Apron, dan Peralatan IPA. Media pembelajaran IPA yang ada di laboratorium tersebut dapat digunakan untuk percobaan sebanyak 121 percoban IPA.

Sedangkan berdasarkan dokumen di jurusan PGMI jumlah mahasiswa angkatan pertama 74 terbagi dalam dua kelas. Setiap kelas rata-rata 37 mahasiswa, dengan asumsi bahwa setiap percobaan, dalam satu kelompok terdiri 5 - 6 mahasiswa maka setiap percobaan terdiri dari 7 kelompok. Ini atrinya bahwa setiap kali percobaan dalam judul yang sama laboratorium harus menyediakan 7 set peralatan setiap percobaan. Namun demikian ada beberapa peralatan yang ditujukan dalam kegiatan demontrasi maka hanya dibutuhkan 2 set. Secara lebih terperinci terlihat dalam tabel berikut ini. 


\section{Kategori KIT IPA}

Tabel. 3. KIT IPA

\begin{tabular}{|c|l|c|c|c|c|c|}
\hline No & \multicolumn{1}{|c|}{ KIT IPA } & $\begin{array}{c}\text { Jumlah } \\
\text { Percobaan }\end{array}$ & $\begin{array}{c}\text { Jumlah } \\
\text { a alat }\end{array}$ & $\begin{array}{c}\text { Jumlah } \\
\text { set }\end{array}$ & $\begin{array}{c}\text { Jumlah Ideal } \\
\text { Kebutuhan (set) }\end{array}$ & $\begin{array}{c}\text { Kekuran } \\
\text { gan }\end{array}$ \\
\hline 1 & KIT Neraca & 3 & 20 & 3 & 7 & 4 \\
\hline 2 & KIT Mineral & 8 & 12 & 2 & 7 & 5 \\
\hline 3 & KIT Bunyi & 2 & 6 & 3 & 7 & 4 \\
\hline 4 & $\begin{array}{l}\text { KIT Batu Bara } \\
\text { dan Minyak Bumi }\end{array}$ & 4 & 9 & 1 & 7 & 6 \\
\hline 5 & KIT Cahaya & 8 & 35 & 7 & 7 & 0 \\
\hline 6 & $\begin{array}{l}\text { KIT Pesawat } \\
\text { Sederhana }\end{array}$ & 6 & 56 & 7 & 7 & 0 \\
\hline 7 & KIT Kalor & 7 & 34 & 2 & 7 & 5 \\
\hline 8 & KIT Magnet & 3 & 21 & 7 & 7 & 0 \\
\hline 9 & KIT Listrik & 8 & 264 & 7 & 7 & 0 \\
\hline \multicolumn{2}{|l|}{ Jumlah } & $\mathbf{4 9}$ & $\mathbf{4 5 3}$ & $\mathbf{3 9}$ & $\mathbf{6 3}$ & $\mathbf{2 4}$ \\
\hline
\end{tabular}

Dari data di atas tampak bahwa media pembelajaran IPA dengan kategori KIT IPA dengan rincian jumlah percobaan yang dapat dilakukan dengan yaitu 49 judul percobaan, dengan jumlah peralatan 453 buah yang terdiri dari 39 set. Namun demikian karena kebutuhan ideal 63 set sehingga masih diperlukan penambahan sejumlah 24 set.

\section{Kategori KIT IPA Terintegrasi}

Tabel. 4. KIT IPA Terintegrasi

\begin{tabular}{|l|l|c|c|c|c|c|}
\hline No & Kategori Media Lab & $\begin{array}{c}\text { Jumlah } \\
\text { Percobaan }\end{array}$ & $\begin{array}{c}\text { Jumlah } \\
\text { @ alat }\end{array}$ & $\begin{array}{c}\text { Jumlah } \\
\text { set }\end{array}$ & $\begin{array}{c}\text { Jumlah Ideal } \\
\text { Kebutuhan } \\
\text { (set) }\end{array}$ & $\begin{array}{c}\text { Kekuran } \\
\text { gan }\end{array}$ \\
\hline 1 & KIT IPA Terintegrasi & 21 & 83 & 1 & 2 & 1 \\
\hline
\end{tabular}

Berdasarkan data di atas, jumlah percobaan yang dapat dilakukan dengan KIT IPA terintergrasi yaitu 21 judul percobaan. Jumlah alat terdiri dari 83 buah dalam satu set. Namun demikian karena idelnya 2 set maka masih diperlukan penambahan 1 set. 
3. Model

Tabel. 5. Model

\begin{tabular}{|l|c|c|c|c|c|c|}
\hline No & $\begin{array}{c}\text { Kategori Media } \\
\text { Lab }\end{array}$ & $\begin{array}{c}\text { Jumlah } \\
\text { Percobaan }\end{array}$ & $\begin{array}{c}\text { Jumlah } \\
\text { a } \text { alat }\end{array}$ & $\begin{array}{c}\text { Jumlah } \\
\text { set }\end{array}$ & $\begin{array}{c}\text { Jumlah Ideal } \\
\text { Kebutuhan (set) }\end{array}$ & $\begin{array}{c}\text { Kekuran } \\
\text { gan }\end{array}$ \\
\hline 1 & Model & 12 & 30 & 12 & 12 & 0 \\
\hline
\end{tabular}

Dari data tersebut di atas, menunjukan bahwa model ada sejumlah 12 set yang terdiri dari 30 buah alat yang dapat digunakan untuk 12 percobaan atau pengamatan.

\section{Poster}

Tabel. 6. Poster

\begin{tabular}{|l|l|c|c|c|c|c|}
\hline No & $\begin{array}{c}\text { Kategori Media } \\
\text { Lab }\end{array}$ & $\begin{array}{c}\text { Jumlah } \\
\text { Percobaan }\end{array}$ & $\begin{array}{c}\text { Jumlah } \\
\text { @ alat }\end{array}$ & $\begin{array}{c}\text { Jumlah } \\
\text { set }\end{array}$ & $\begin{array}{c}\text { Jumlah Ideal } \\
\text { Kebutuhan (set) }\end{array}$ & $\begin{array}{c}\text { Kekuran } \\
\text { gan }\end{array}$ \\
\hline 1 & Poster & 20 & 30 & 20 & 20 & 0 \\
\hline
\end{tabular}

Dari data tersebut di atas, menunjukan bahwa poster ada sejumlah 20 set yang terdiri dari 30 buah alat yang dapat digunakan untuk 20 percobaan atau pengamatan.

\section{Kartu}

Tabel. 7. Kartu

\begin{tabular}{|l|l|c|c|c|c|c|}
\hline No & $\begin{array}{c}\text { Kategori Media } \\
\text { Lab }\end{array}$ & $\begin{array}{c}\text { Jumlah } \\
\text { Percobaan }\end{array}$ & $\begin{array}{c}\text { Jumlah } \\
\text { @ alat }\end{array}$ & $\begin{array}{c}\text { Jumlah } \\
\text { set }\end{array}$ & $\begin{array}{c}\text { Jumlah Ideal } \\
\text { Kebutuhan (set) }\end{array}$ & $\begin{array}{c}\text { Kekuran } \\
\text { gan }\end{array}$ \\
\hline 1 & Kartu & 11 & 119 & 11 & 11 & 0 \\
\hline
\end{tabular}

Dari data tersebut di atas, menunjukan bahwa kartu ada sejumlah 11 set yang terdiri dari 119 buah alat yang dapat digunakan untuk 11 percobaan atau pengamatan.

\section{Apron}

Tabel.8. Apron

\begin{tabular}{|l|l|c|c|c|c|c|}
\hline No & $\begin{array}{c}\text { Kategori Media } \\
\text { Lab }\end{array}$ & $\begin{array}{c}\text { Jumlah } \\
\text { Percobaan }\end{array}$ & $\begin{array}{c}\text { Jumlah } \\
\text { @ alat }\end{array}$ & $\begin{array}{c}\text { Jumlah } \\
\text { set }\end{array}$ & $\begin{array}{c}\text { Jumlah Ideal } \\
\text { Kebutuhan (set) }\end{array}$ & $\begin{array}{c}\text { Kekuran } \\
\text { gan }\end{array}$ \\
\hline 1 & Apron & 3 & 13 & 2 & 2 & 0 \\
\hline
\end{tabular}


Dari data tersebut di atas, menunjukan bahwa apron ada sejumlah 2 set yang terdiri dari 13 buah alat yang dapat digunakan untuk 3 percobaan atau simulasi.

\section{Peralatan IPA}

Tabel. 9. Peralatan IPA

\begin{tabular}{|l|l|c|c|c|c|c|}
\hline No & $\begin{array}{c}\text { Kategori } \\
\text { Media Lab }\end{array}$ & $\begin{array}{c}\text { Jumlah } \\
\text { Percobaan }\end{array}$ & $\begin{array}{c}\text { Jumlah } \\
\text { a alat }\end{array}$ & Jumlah set & $\begin{array}{c}\text { Jumlah Ideal } \\
\text { Kebutuhan (set) }\end{array}$ & Kekurangan \\
\hline 1 & $\begin{array}{l}\text { Peralatan } \\
\text { IPA }\end{array}$ & 5 & 9 & $\begin{array}{c}\text { Variasi } \\
\text { (Mikroskop } \\
\text { ada 2) }\end{array}$ & $\begin{array}{c}\text { Variasi (Jumlah } \\
\text { kebutuhan } \\
\text { Mikroskop 7) }\end{array}$ & $\begin{array}{c}\text { Variasi } \\
\text { (Kekurangan } \\
\text { Mikroskop 5) }\end{array}$ \\
\hline
\end{tabular}

Dari data tersebut di atas, menunjukan bahwa alat peraga IPA ada sejumlah 9 buah alat yang dapat digunakan untuk 5 percobaan. Namun masih dibutuhan penambahan alat berupa mikroskop 5 buah.

Dari data di atas secara ringkas dapat dibuat tabel sebagai berikut.

Tabel. 10. Jumlah Media Alat Peraga

\begin{tabular}{|l|l|c|c|c|c|c|}
\hline No & $\begin{array}{c}\text { Kategori Media } \\
\text { Lab }\end{array}$ & $\begin{array}{c}\text { Jumlah } \\
\text { Percobaan }\end{array}$ & $\begin{array}{c}\text { Jumlah } \\
\text { @ alat }\end{array}$ & $\begin{array}{c}\text { Jumlah } \\
\text { set }\end{array}$ & $\begin{array}{c}\text { Jumlah } \\
\text { Ideal } \\
\text { Kebutuhan } \\
\text { (set) }\end{array}$ & $\begin{array}{c}\text { Kekurang } \\
\text { an }\end{array}$ \\
\hline 1 & KIT IPA & 49 & 453 & 39 & 63 & 24 \\
\hline 2 & KIT IPA Terintegrasi & 21 & 83 & 1 & 2 & 1 \\
\hline 3 & Model & 12 & 30 & 12 & 12 & 0 \\
\hline 4 & Poster & 20 & 30 & 20 & 20 & 0 \\
\hline 5 & Kartu & 3 & 11 & 11 & 11 & 0 \\
\hline 6 & Apron & 5 & 9 & $\begin{array}{c}\text { Variasi } \\
\text { (Mikrosk } \\
\text { op ada 2) }\end{array}$ & $\begin{array}{c}\text { Variasi } \\
\text { (Jumlah } \\
\text { kebutuhan } \\
\text { Mikroskop } \\
7\end{array}$ & $\begin{array}{c}\text { Perariasi } \\
\text { (Kekurang } \\
\text { an } \\
\text { Mikroskop } \\
5)\end{array}$ \\
\hline & & & & & & \\
\hline
\end{tabular}

Dari data di atas menunjukan bahwa laboratorium PGMI memiliki 85 set peralatan yang terdiri dari 737 buah alat dan dapat digunakan untuk 121 judul percobaan. Namun demikian edialnya memiliki 110 set, sehingga masih kekurangan 25 set peralatan IPA dan ditambah 5 buah mikroskop. 
Kekurangan 25 set peralatan percobaan IPA tersbut dengan rincian sebagai berikut: KIT IPA kurang 24 set ( KIT Neraca 4 set, KIT Mineral 5 set, KIT Bunyi 4 set, KIT Batu Bara 6 set, dan KIT Kalor 5 set) dan KIT IPA terintegrasi kurang 1 set, dan 5 buah mikroskop.

\section{Kesimpulan}

Berdasarkan analisis data dan pembahasan di atas dapat di tarik kesimpulan sebagai berikut: 1) Laboratorium PGMI FITK IAIN Surakarta khususnya untuk laboratorium IPA memiliki 85 set peralatan yang terdiri dari 737 buah alat dan dapat digunakan untuk 121 judul percobaan IPA. 2) Kebutuhan tambahan yang diperlukan yaitu 25 set peralatan percobaan IPA, dengan rincian sebagai berikut: KIT IPA kurang 24 set, yang terdiri dari KIT Neraca 4 set, KIT Mineral 5 set, KIT Bunyi 4 set, KIT Batu Bara 6 set, dan KIT Kalor 5 set, dan KIT IPA terintegrasi kurang 1 set, serta 5 buah mikroskop. 


\section{Daftar Pustaka}

Ace Suryadi dan H.A.R. Tilaar. 1994. Analisis Kebijakan Pendidikan, Suatu Pengantar. Bandung : Remaja Rosdakarya.

Aldrin E. Sweeney \& Jeffrey A. Paradis. 2003. Addressing the Professional Preparation of Future Science Teachers to Teach Hands - on Science : a Pilot Study of a Labora-tory Model. 80 (2), 171 - 173.

Amy J. Phelps \& Cherin Lee. 2003. The Power of Practice : What Students Learn from How We Teach. Journal of Chemical Education, 80 (7), 829 - 832.

Arsyad, Azhar. 2006. Media Pembelajaran. Jakarta : Rineka Cipta.

Badudu. 2001. Kamus Besar Bahasa Indonesia.Jakarta : Pustaka Harapan.

Bateman, S.T. dan Zeithami, P.C. 1990. Management Function and Strategy. Boston : Homewood.

Borg, W.R. and Gall, M.D. 1983. Educational Research: An introduction. Four edition. New York: Longman. Islam Negeri (IAIN) 2013. Buku Panduan Akademik 2012-2013. Surakarta Institut Agama 2014. Draf Buku Pedoman Perkuliahan Jurusan PGMI. Surakarta Institut Agama Islam Negeri (IAIN)

Depdikbud. 1979. Pengelolaan Laboratorium Sekolah dan Manual Alat IPA. Jakarta : Direktorat Pendidikan Menengah Umum. .1994. Petunjuk Pelaksanaan Proses Belajar-Mengajar. Jakarta : Direktorat Pendidikan Menengah Umum. .1999. Panduan Manajemen Sekolah. Jakarta : Direktorat Pendidikan Mene-ngah Umum.

Flinn Scientific. 2004. 45 Ideas, Tips, and Hints to Help You Design a Safe and Efficient Chemistry. http://www.Flinnsci.com/index.Asp. Diakses tanggal 21 Juli 2009.

Hamalik, Oemar. 1994. Media Pendidikan, Bandung : Citra Aditya Bakri

Hall, F.J. 1986. Experimental Chemistry. Massachusetts : D.C. Heath and Company.

John W. Hansen \& Gerald G. Lovedahl. 2004. Developing Technology Teachers : Questio-ning the Industrial Tool Use Model. Journal of Technology Education. 15 (2), $20-32$.

| Volume. 1, No. 1, Januari-Juni 2016 
Koesmadji. 2004. Teknik Laboratorium. Bandung : FMIPA UPI

Moejadi. 1994. Model Pemanfaatan KIT IPA SD yang Efektif Untuk Peningkatan Kualitas Pembelajaran IPA. Jakarta : Lembaga Penelitian IKIP Yogyakarta.

Mel Silberman. 2002. Active Learning : 101 Strategies to Teach any Subject (Terjemahan Sarjuli, Adzfar Ammar, Sutrisno, et. Al.). Boston : Allyn and Bacon. (buku asli diterbitkan tahun 1996).

Moh. Amien. 1997. Buku Pedoman Laboratorium dan Petunjuk Praktikum Pendidikan IPA Umum (General Science) untuk LPTK. Jakarta : Depdikbud.

Ratna Wilis Dahar. 1986. Pengelolaan Pengajaran Kimia. Jakarta : Karunika.

Rustaman, Nuryani. 2005. Strategi Belajar Mengajar Biologi. Malang: IKIP Malang (UM) Press.

Subiyanto. 1998. Pendidikan Ilmu Pengetahuan Alam. Jakarta : Depdikbud.

Sudaryanto, Indrawati, dan Endang Kowara. 1998. Pengelolaan laboratorium IPA dan Instalasi Listrik. Jakarta : Depdikbud.

Sugiyono. 2010. Metode Penelitian Kuantitatif, Kualitatif, dan $R \&$ D. Jogjakarta: Alfabeta

Suyatman. 2013. Pengembangan Perkuliahan Laboratorium IPA di Prodi PGRA. FITK IAIN Surakarta.

Subiyanto. 1998. Pendidikan Ilmu Pengetahuan Alam. Jakarta : Depdikbud.

Sudaryanto, Indrawati, dan Endang Kowara. 1998. Pengelolaan laboratorium IPA dan Instalasi Listrik. Jakarta : Depdikbud.

Sudjana. 2000. Manajemen Program Pengajaran. Bandung : Falah Production.

Trisnoherawati, Nanik. 2004. Pengaruh Kit IPA Terhadap Prestasi Belajar Siswa.[Google] tersedia: http://www.damandiri.or.id/file/naniktunpabs bab II Pdf

Terry, R.G. 1977. Principles of Management. Seventh Edition. Illionis : Ricard D. Irwin Inc.Homewood.

The General Safety Committee. 1954. Guide for Safety in the Chemical Laboratory. New York : D. Van Nostrand Company. Inc. 